\title{
A POLÍTICA RECENTE DE FUNDOS PARA O FINANCIAMENTO DA EDUCAÇÃO E SEUS EFEITOS NO PACTO FEDERATIVO
}

\author{
José Marcelino de Rezende Pinto
}

\begin{abstract}
RESUMO: Este artigo procura analisar o impacto que a recente política de fundos para o financiamento da educação básica (FUNDEF e FUNDEB) produziu na divisão de responsabilidades pelo atendimento educacional entre estados e municípios. Parte-se de uma análise do caráter peculiar dos municípios na federação brasileira e avaliam-se as mudanças recentes no perfil de seu atendimento educacional, discutindo-se as principais características e os prováveis impactos do FUNDEB, assim como os desafios que se colocam para o país para a construção de uma escola pública de qualidade.
\end{abstract}

Palavras-chave: Fundos educacionais. FUnDEB. FUNDEF. Educação de qualidade.

\section{BRAZILIAN NEW FUNDS FOR EDUCATION POLICY AND ITS IMPACTS ON THE FEDERATIVE PACT}

ABSTRACT: This paper analyzes the Brazilian policy of financing school through special funds (FUNDEF and FUNDEB), and discusses its effects on the educational offer by states and municipalities. Special attention is put on the newly (2007) approved FUNDEB (Fund for the Maintenance and Development of Basic Education) and its main characteristics and impacts on education quality. Finally, the great challenges to improve public school quality are also discussed.

Key words: Educational funds. FUNDEB. FUNDEF. Quality education.

Doutor em Educação e professor da Faculdade de Filosofia, Ciências de Letras da Universidade de São Paulo (UsP, Campus de Ribeirão Preto).E-mail: jmrpinto@ffclrp.usp.br. 
A política recente de fundos para o financiamento da educação e seus efeitos...

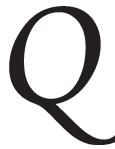

uando analisamos a distribuição de responsabilidades pela educação básica entre estados e municípios ao longo dos últimos anos no Brasil, tendo por base os dados do Censo Escolar do INEP, constatamos o grande aumento do peso das matrículas da rede municipal. Assim é que, se no período de 1991 a 1996 as matrículas municipais respondiam por cerca de $37 \%$ do total da rede pública,. ${ }^{1}$ com a entrada em vigor, a partir de 1997, do Fundo de Manutenção e Desenvolvimento do Ensino Fundamental e de Valorização do Magistério (FUNDEF), nota-se um progressivo aumento da participação da rede municipal, que chega em 2006 atendendo 52\% das matrículas públicas.

\section{Gráfico 1}

Responsabilidade pelo atendimento da educação básica 1991-2006

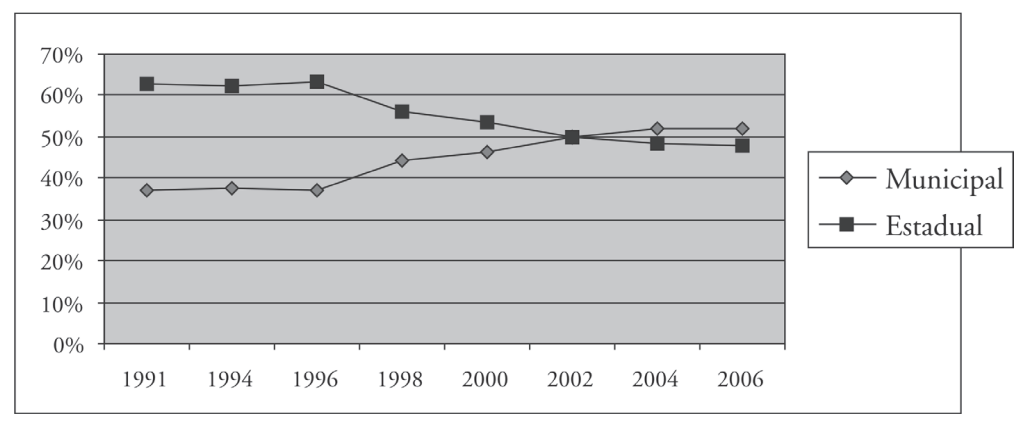

Esta tendência crescente do aumento de responsabilidade dos municípios pelo atendimento educacional fica ainda mais evidente quando analisamos a evolução das matrículas no ensino fundamental, que é apresentada no Gráfico 2, para as diferentes regióes do país. Constata-se que em todas as regiões a municipalização avançou, de tal forma que a rede municipal, que, em 1991, era responsável por 35\% das matrículas públicas do ensino fundamental (um patamar que remonta à década de 1950), passou a responder por $60 \%$ dessas matrículas em 2006. O Nordeste é a região onde esse processo mais avançou, atingindo, neste último ano, 77\% das matrículas. Esta situação é particularmente preocupante, pois é nessa região que se encontram os 
municípios mais pobres do país, como veremos. Já na região Sudeste deu-se o maior aumento relativo, saltando de $21 \%$ para $51 \%$ do total de matrículas públicas.

\section{Gráfico 2}

Evolução do atendimento da rede municipal no ensino fundamental

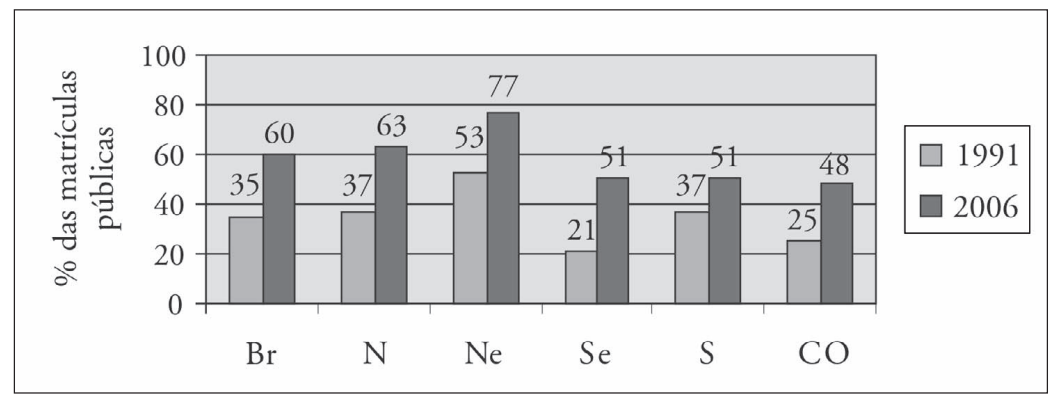

Os dados do Censo Escolar permitem constatar também que o crescimento do atendimento educacional deu-se nas diferentes fases do ensino fundamental. Assim é que, no mesmo período, a participação das matrículas municipais nas séries iniciais saltou de $43 \%$ para $76 \%$ do total da rede pública, ao passo que nas séries finais essa participação saiu de $17 \%$ em 1991, atingindo a cifra de 42\% em 2006. Estes dados chamam a atenção para um outro problema: para poder concluir o ensino obrigatório, crianças e jovens brasileiros precisam freqüentar escolas de diferentes redes de ensino que, em geral, possuem grandes diferenças de qualidade e padrões de avaliação entre si, o que torna mais difícil ainda a conclusão do ensino fundamental com êxito.

Como já comentamos, o principal fator responsável por esta mudança no perfil de atendimento educacional no país foi o FUNDEF. Ao atrelar parcela dos recursos vinculados à educação à matrícula no ensino fundamental regular, este fundo induziu um processo de municipalização sem precedentes no Brasil. A este efeito se soma também o impacto negativo no atendimento da educação infantil e na educação de jovens e adultos (EJA), conforme apontam vários estudos (Didonet, 2006; Pinto, 2006; Arelaro \& Kruppa, 2002). 
A política recente de fundos para o financiamento da educação e seus efeitos...

Esta mudança desencadeada pelo FUNDEF no padrão de divisão de responsabilidades, contudo, no nosso entendimento, pouco contribuiu para aumentar a eficiência de gestão do sistema e menos ainda a qualidade do ensino. Em geral, não houve consulta à comunidade escolar e os critérios de decisão foram essencialmente monetários: de um lado, os estados querendo reduzir seus alunos, de outro os municípios querendo ampliar suas receitas. A preocupação com a qualidade do ensino esteve, em geral, ausente em boa parte dos convênios de municipalização. A maneira apressada como se deu o processo gerou um grande desperdício na alocação dos profissionais do magistério. Assim, em São Paulo, por exemplo, há um enorme contingente de professores efetivos da rede estadual que está ocioso, porque nas localidades onde trabalhavam esses professores as escolas foram municipalizadas e houve concursos para contratação de novos professores pela rede municipal.

A Tabela 1 dá uma clara amostra do pequeno impacto do FUNDEF no que se refere à melhoria das condições de oferta do ensino fundamental. Nela é apresentado o porcentual de escolas públicas que dispõem de alguns insumos, os quais são imprescindíveis para uma escola que procure assegurar condiçóes satisfatórias de ensino. Os dados apresentados na tabela, construída a partir de dados do Censo Escolar, mostram que, em 2005, apenas cerca de 1/5 das escolas brasileiras apresenta biblioteca (na verdade, sala de leitura) ou quadras de esporte, somente $12 \%$ possuem laboratório de informática, $15 \%$ estão ligadas

\section{Tabela 1}

(Recursos existentes em escolas públicas de ensino fundamental por região - \% do total: 2005)

\begin{tabular}{|c|c|c|c|c|c|}
\hline & Biblioteca & Lab. Informática & Lab. Ciências & Quadra de Esp. & Internet \\
\hline $\mathrm{Br}$ & $19 \%$ & $12 \%$ & $6 \%$ & $23 \%$ & $15 \%$ \\
\hline $\mathrm{N}$ & $10 \%$ & $4 \%$ & $1 \%$ & $9 \%$ & $4 \%$ \\
\hline $\mathrm{Ne}$ & $9 \%$ & $4 \%$ & $1 \%$ & $8 \%$ & $4 \%$ \\
\hline $\mathrm{Se}$ & $27 \%$ & $29 \%$ & $12 \%$ & $48 \%$ & $39 \%$ \\
\hline $\mathrm{S}$ & $55 \%$ & $23 \%$ & $19 \%$ & $49 \%$ & $26 \%$ \\
\hline $\mathrm{CO}$ & $30 \%$ & $17 \%$ & $5 \%$ & $39 \%$ & $23 \%$ \\
\hline
\end{tabular}

Fonte: INEP. 
à internet (mas, em geral, apenas para uso administrativo) e somente 6\% têm um laboratório de ciências. Nas regiōes Norte e Nordeste a presença de boa parte destes recursos aproxima-se de zero, melhorando um pouco a oferta nas regióes Sudeste e Sul, mas ainda muito aquém do aceitável.

Uma outra conseqüência deste aumento da participação municipal nas matrículas da educação é que se rompeu o equilíbrio entre alunos atendidos e capacidade financeira dos municípios. Assim é que, embora os municípios já possuam uma matrícula na educação básica maior que aquela apresentada pelos estados, sua receita líquida de impostos é bem inferior àquela obtida pelos estados (cerca de três quartos), o que demonstra uma situação de grande fragilidade do atual sistema de financiamento. Quando analisamos esta distribuição nas diferentes regiōes do país, os problemas se acirram. Assim é que, em estados como MA, CE, AL e PA (exatamente aqueles onde o investimento por aluno é mínimo), constata-se que os governos estaduais, embora tenham 1,5 vez mais recursos de impostos que os governos municipais, são responsáveis por menos da metade dos alunos. O sistema de financiamento só não entrou em colapso porque o FUNDEF, e agora o FUNDEB, transferem recursos de uma esfera de governo para a outra, mas considerando que os fundos são transitórios, montou-se uma bomba de efeito retardado com data certa para explodir: 31 de dezembro de 2020, quando finda o FUNDEB. Se nenhuma medida de caráter permanente for tomada neste ínterim, o país viverá naquela data uma grave crise no pacto federativo, pois os municípios ficarão com um número de alunos muito superior à sua capacidade de financiamento. Para se ter uma idéia do desequilíbrio, tomando por base a matrícula de 2006, estima-se que com o FUNDEB os estados transferirão cerca de $\mathrm{R} \$ 9$ bilhões aos municípios a partir do terceiro ano de vigência do novo fundo (Bremaeker, 2007).

Outro efeito importante do FUNDEF no que se refere ao pacto federativo relaciona-se a mudanças nos critérios de distribuição da receita tributária entre os municípios de um mesmo estado. E aqui duas tendências se observam: uma positiva, do ponto de vista da justiça fiscal, e outra negativa. A mudança positiva refere-se ao critério de distribuição do ICMS, que é o tributo de maior arrecadação no país e principal fonte de recursos do FUNDEF e do FUNDEB. Nos termos da legislação, o principal critério que rege a distribuição da cota municipal do ICMS 
A política recente de fundos para o financiamento da educação e seus efeitos...

(que corresponde a 25\% do total deste imposto) entre os municípios de um mesmo estado é a respectiva arrecadação. É por isso que os municípios mais industrializados são aqueles que apresentam as maiores receitas per capita do país, já que a maior parte da arrecadação do ICMS advém da atividade industrial. Ora, o FUNDEF (e o FUNDEB com maior impacto) altera esse critério no que se refere àquela parcela do tributo que compõe este fundo, já que a distribuição se dava, no caso do FUNDEF, pela proporção de alunos matriculados no ensino fundamental regular da respectiva rede e, no caso do FUNDEB, pela matrícula na educação básica. Em termos concretos, essa mudança de critério significa que os municípios com maior receita de ICMS tendem a transferir recursos para aqueles de menor receita. Entendemos como positivo este efeito "Robin Hood" porque, uma vez que esse tributo tem natureza indireta e é pago, portanto, pelo consumidor final, não é justo que alguns poucos municípios mais industrializados se beneficiem de um tributo que é pago por todos, inclusive por habitantes de outros estados, mas esta é uma outra polêmica que está além dos limites deste artigo. Contudo, o FUNDEF apresenta também um efeito "Robin Hood" às avessas e que atinge principalmente os pequenos municípios, em especial aqueles situados nas regióes mais pobres do país e cuja receita principal vem das transferências da União propiciadas pelo Fundo de Participação dos Municípios (FPM). Como aponta estudo elaborado por Bremaeker (2003), em 2002, 94\% dos municípios com população inferior a 2 mil habitantes perderam recursos com o FUNDEF; essa perda foi de $72,5 \%$ para os municípios com população entre 2 mil e 5 mil habitantes. Cabe ressaltar que, segundo o autor, essas perdas aconteceram mesmo em municípios com elevado grau de municipalização do ensino fundamental. A causa desse efeito perverso provocado pelo FUNDEF, e que será acentuado pelo FUNDEB, relaciona-se aos critérios de distribuição do FPM, segundo os quais os municípios de pequeno porte recebem um valor "per capita" proporcionalmente mais elevado que o daqueles de maior população. A título de comparação, em 2002 , esse valor era de $\mathrm{R} \$ 1.093$ per capita para municípios com até 2 mil habitantes, $\mathrm{R} \$ 515$ para aqueles com população entre 2 mil e 5 mil habitantes e R $\$ 276$ para aqueles com população entre 5 mil e $10 \mathrm{mil}$ habitantes. Já para municípios com população superior a 1 milhão de habitantes, seu valor per capita era de apenas $\mathrm{R} \$ 32$ (Bremaeker, 2003).

Este impacto regressivo dos fundos no FPM nos leva a uma rápida discussão sobre o efeito do tamanho dos municípios no financiamento 
da educação. Em 2001, segundo dados do Censo do IBGE, 25\% dos municípios brasileiros possuíam menos de 5 mil habitantes; $73 \%$ possuíam menos de 20 mil habitantes, embora respondessem, respectivamente, por $2,7 \%$ e $19,7 \%$ do total da população do país. No outro extremo, os municípios com mais de 500 mil habitantes $(0,5 \%$ do total de municípios) respondiam por $28 \%$ da população e aqueles com mais de 100 mil habitantes ( $4 \%$ do total) abrigavam $51 \%$ da população. Além dos já citados problemas no FPM, esta predominância de municípios de pequeno porte demográfico gera um outro problema: em geral sua receita tributária própria é muito pequena, uma vez que os tributos municipais mais importantes (IPTU e ISS), pela sua própria natureza, só apresentam valores significativos em municípios de grande porte e de elevado grau de urbanização. Estudo feito pelo Instituto Brasileiro de Administração Municipal (IBAM) mostra que, em 2003, ao passo que os municípios com menos de 50 mil habitantes apresentavam uma receita tributária inferior a $R$ \$ 50/habitante, nos municípios com mais de 1 milhão de habitantes esse valor é superior a $R \$ 200 /$ habitante, chegando a R \$423/habitante nos municípios com 5 milhôes ou mais de habitantes (Bremaeker, 2004). Com o FUNDEB esta questão terá um impacto muito sério, pois, como houve uma subestimação real do valor de ponderação dos alunos das creches, como veremos mais adiante, a única fonte adicional de recursos que os municípios terão para garantir um mínimo de qualidade para esta etapa da educação será a sua receita tributária própria. Ora, o mesmo estudo do IBAM indica que, em 2003, nos municípios com até 20 mil habitantes $(73 \%$ do total), a receita tributária própria era inferior a $5 \%$ da receita orçamentária total. Portanto, a maioria dos municípios brasileiros terá uma margem de manobra muito pequena para viabilizar uma educação infantil de qualidade.

Um outro problema que a política de fundos trouxe à luz se refere às dimensões das escolas. Como o sistema de financiamento é estruturado tendo por base um valor disponível por aluno, uma questão crucial refere-se às economias de escala. Assim, quanto mais alunos possuírem as escolas (e as turmas) mais se faz com o mesmo recurso. Dessa forma, de um lado há a tendência em aumentar o número de alunos por turma e, de outro, há o risco de se subfinanciar as escolas de pequeno porte. O problema surge em especial nas escolas rurais, mas não só nelas. Segundo dados do Censo Escolar do INEP, em 2005 
A política recente de fundos para o financiamento da educação e seus efeitos...

existiam 41 mil escolas públicas (28\% do total) com apenas uma sala de aula e 62 mil ( $43 \%$ do total) atendiam até 50 alunos. Essas escolas, em sua maioria, atendem as séries iniciais do ensino fundamental, e fica evidente que, com este baixo número de alunos, a tendência dos administradores escolares para fazer os recursos "renderem" é montar turmas multisseriadas, com apenas um professor, com os efeitos já conhecidos na qualidade do ensino oferecido. E aqui mais uma vez os municípios é que são os mais atingidos, pois a sua rede responde por $87 \%$ das escolas de ensino fundamental com até 50 alunos. Além disso, $90 \%$ dessas mesmas escolas estão na zona rural. Sua distribuição apresenta também grande disparidade entre as regiōes geográficas, de tal forma que no Norte e Nordeste as escolas com menos de 50 alunos representam, respectivamente, $59 \%$ e $51 \%$ do total das escolas públicas. Já no Sudeste e Sul estes índices são de, respectivamente, 26\% e $30 \%$, ficando em $22 \%$ na região Centro-Oeste. Outro dado relevante é que das 90 mil escolas rurais que ofereciam o ensino fundamental, em 2005, 57\% delas encontravam-se no Nordeste e $20 \%$ na região Norte. Juntam-se aqui dois fatores, tamanho da escola e localização na zona rural, que representam um forte impacto nos custos e que foram pouco considerados no FUNDEF, assim como no FUNDEB, no que se refere às ponderaçôes para o ano de 2007. Um agravante é que boa parte dessas escolas se encontra exatamente nas regiōes mais pobres do país, onde os recursos disponibilizados pelos fundos atingem seus menores valores per capita.

E neste ponto chegamos à questão crucial da política de fundos: Qual o valor disponível por aluno? O Gráfico 3 apresenta uma comparação entre os valores médios por aluno propiciados pelo FUNDEF, em 2006, seu último ano de existência, tendo por base dados da Secretaria do Tesouro Nacional (STN), assim como as estimativas para o valor/aluno do FUNDEB, nas séries iniciais do ensino fundamental (zona urbana), conforme consta no Decreto n. 6.091, de 24 de abril de 2007, que divulga os parâmetros de operacionalização do FUNDEB para o ano de 2007.

A primeira constatação a se tirar do Gráfico 3, no que se refere aos valores/aluno do FUNDEF, é a grande disparidade entre os estados da Federação. Mesmo desconsiderando o valor de Roraima, que, por ter baixa densidade populacional, distorce um pouco a média, o valor/aluno de São Paulo é superior ao dobro daquele praticado pelos estados de Maranhão, Pará, Alagoas, Bahia, Ceará e Piauí. 


\section{Gráfico 3}

R\$ por aluno: FUNDEF (Média) x FUNDEB (séries iniciais)

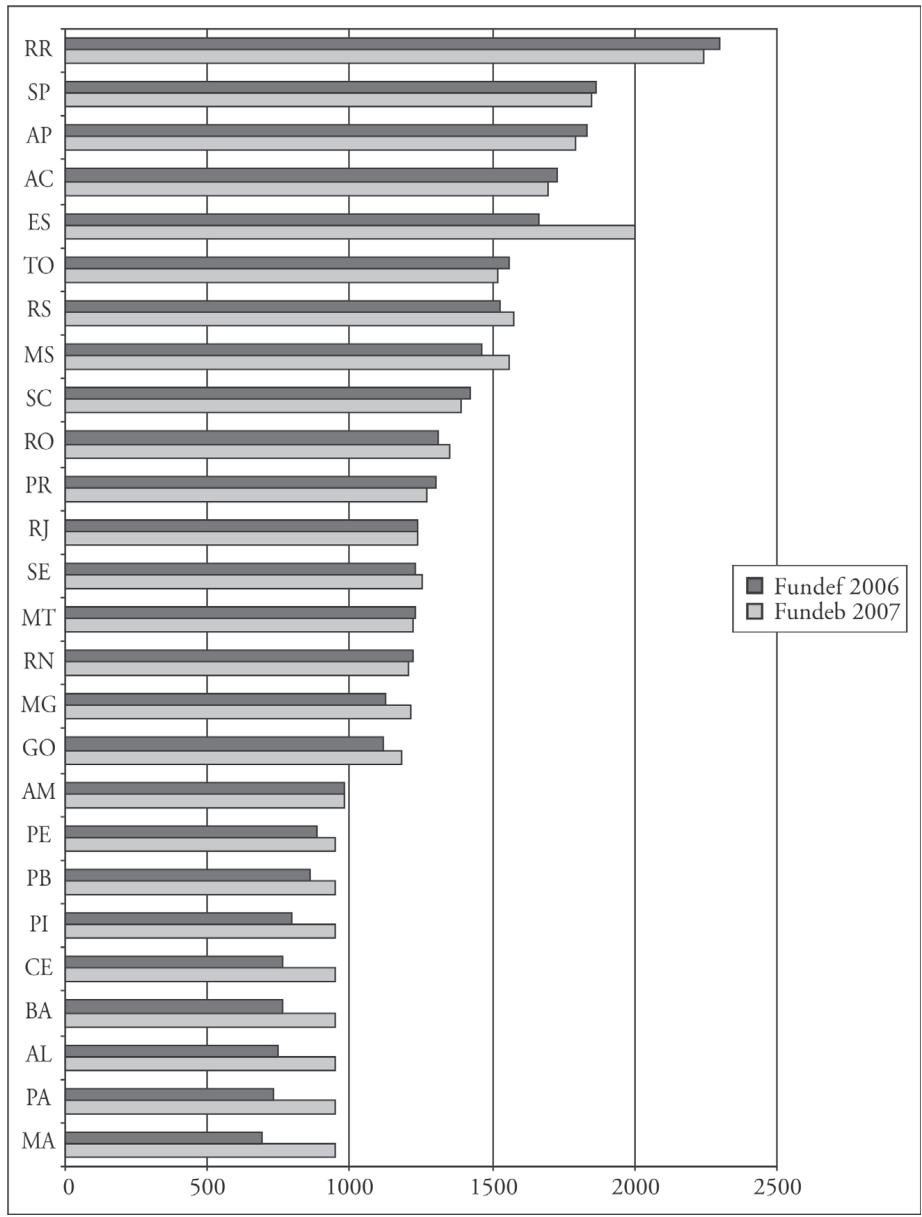

A segunda constatação quanto ao FUNDEF é que ele propiciou valores por aluno muito reduzidos. Basta dizer que em 11 estados (MA, PA, AL, BA, CE, PI, PB, PE, AM, GO, MG) da Federação ele disponibilizou recursos mensais inferiores a $\mathrm{R} \$ 100$ por aluno, e em 6 estados (MA, PA, 
A política recente de fundos para o financiamento da educação e seus efeitos...

AL, BA, CE, PI) esses valores foram inferiores a R\$ 70/mês. Mesmo considerando o valor médio do FUNDEF, que em 2006 foi de cerca de $\mathrm{R} \$ 100$, quantia que, segundo a Emenda Constitucional n. 14 que criou o fundo, deveria ser o valor mínimo nacional, constata-se que é um valor muito inferior ao praticado por boa parte das escolas privadas e é cerca da metade do valor praticado pelo Chile, e $10 \%$ do valor praticado pelos Estados Unidos, quando se considera a paridade das moedas (OCDE, 2005). Um outro exemplo: quem possui um filho estudando na rede privada de ensino pode descontar $\mathrm{R} \$ 2$ mil no Imposto de Renda, uma quantia $70 \%$ acima do valor médio propiciado pelo FUNDEF.

Vejamos agora os impactos do FUNDEB no que se refere aos recursos disponíveis por aluno. Os dados do Gráfico 3 indicam que, com exceção do estado do Pará e daqueles da região Nordeste (exceto Rio Grande do Norte e Sergipe) onde haverá uma contribuição mais significativa da União, haverá uma alteração muito pequena nos recursos por aluno. Quando se considera, inclusive, o valor médio por aluno, a tendência com o FUNDEB é haver uma diminuição perante o valor propiciado pelo FUNDEF, mesmo levando em conta um aumento superior a 10 vezes (de R $\$ 314$ milhões, em 2006, para R \$ 4,5 bilhões, em 2009) o da complementação da União, conforme mostra o Quadro 1 (última linha). Isso se explica porque, mesmo considerando que o FUNDEB envolverá recursos totais $43 \%$ superiores àqueles abrangidos pelo FUNDEF, tomando por base o ano de 2006, o número de alunos atingidos pelo novo fundo será $61 \%$ superior.

O novo fundo implicará também uma melhora significativa (acréscimo de cerca de 39\%, tendo por base 2006) em relação ao valor mínimo nacional do FUNDEF. Para o FUNDEB, em 2007, ele está estimado em R\$946,29 por aluno/ano, para as séries iniciais do ensino fundamental. Este valor, que corresponde a menos de $\mathrm{R} \$ 80 /$ mês, é claramente insuficiente para se assegurar um ensino de qualidade. Estudo feito pela Campanha Nacional pelo Direito à Educação (Carreira \& Pinto, 2007) estima que o valor necessário para se garantir um padrão mínimo de qualidade deveria ser, para as séries iniciais do ensino fundamental, de R \$ 1.618/aluno/ano, em valores de 2005, sem considerar as despesas com alimentação escolar. Ora, esta quantia é $71 \%$ superior ao valor estimado para o FUNDEB. Cabe ressaltar também que esta ampliação só ocorreu porque o governo federal nunca cumpriu a EC14, a qual estabelecia que o valor/aluno mínimo do FUNDEF deveria ser, 
pelo menos, igual à média nacional do fundo. Se este preceito houvesse sido cumprido, o mínimo de 2006 seria de cerca de $\mathrm{R} \$ 1.165$ (e não $R \$ 682,60$, que foi o valor fixado pelo governo federal), uma quantia 23\% superior ao valor mínimo do FUNDEB.

O FUNDEB também tende a reduzir as desigualdades entre os estados da Federação. Essa redução, provocada essencialmente pelo aumento da complementação da União, não impede, contudo, que estados como Roraima, Espírito Santo, São Paulo, Rio Grande do Sul, Amapá, Acre, Tocantins tenham à sua disposição recursos por aluno que variam de uma vez e meia a duas vezes àqueles administrados pelos oito estados que ficarão com o valor mínimo (MA, PA, AL, BA, CE, PI, PB, PE).

\section{Quadro 1}

(FUNDEF X FUNDEB: Fonte de recursos e estimativa de valor por aluno - ano-base: 2006)

\begin{tabular}{|c|c|c|c|c|c|}
\hline \multirow[t]{2}{*}{ Composição } & FUNDEF & FUNDEB & FUNDEB & FUNDEB & FUNDEB \\
\hline & 2.006 & Ano 1 & Ano 2 & Ano 3 & Ano 4 \\
\hline ICMS & $15 \%$ & $16,66 \%$ & $18,33 \%$ & $20 \%$ & $20 \%$ \\
\hline FPM & $15 \%$ & $16,66 \%$ & $18,33 \%$ & $20 \%$ & $20 \%$ \\
\hline FPE & $15 \%$ & $16,66 \%$ & $18,33 \%$ & $20 \%$ & $20 \%$ \\
\hline IPI-Ex & $15 \%$ & $16,66 \%$ & $18,33 \%$ & $20 \%$ & $20 \%$ \\
\hline LC $87 / 96$ & $15 \%$ & $16,66 \%$ & $18,33 \%$ & $20 \%$ & $20 \%$ \\
\hline IPVA & $0 \%$ & $6,66 \%$ & $13,33 \%$ & $20 \%$ & $20 \%$ \\
\hline ITCD & $0 \%$ & $6,66 \%$ & $13,33 \%$ & $20 \%$ & $20 \%$ \\
\hline ITR & $0 \%$ & $6,66 \%$ & $13,33 \%$ & $20 \%$ & $20 \%$ \\
\hline Impostos municipais & $0 \%$ & $0 \%$ & $0 \%$ & $0 \%$ & $0 \%$ \\
\hline Complemento da União (R\$) & $314 \mathrm{mi}$ & $2,0 \mathrm{bi}$ & $3,0 \mathrm{bi}$ & $4,5 \mathrm{bi}$ & $10 \%$ \\
\hline Previsão de valores (ref. 2006) & $35,5 \mathrm{bi}$ & $41,1 \mathrm{bi}$ & $45,9 \mathrm{bi}$ & 50,7 bi & \\
\hline Alunos (base 2006) & 30,2 & 37,0 & 42,5 & 48,7 & \\
\hline Per capita $(\mathrm{R} \$)$ & 1.175 & 1.111 & 1.080 & 1.041 & \\
\hline
\end{tabular}

Fonte: Lei n. 11.494/2007 e estimativas do autor.

Os dados apresentados no Gráfico 4 mostram assim que, do ponto de vista dos recursos financeiros, com exceção dos estados de Maranhão, Pará, Alagoas, Bahia e Ceará, o Fundeb terá pouco impacto. Vejamos agora seus efeitos do ponto de vista da gestão dos sistemas de ensino. O Quadro 2 apresenta uma síntese de suas principais características quando comparado com o FUNDEF. 
A política recente de fundos para o financiamento da educação e seus efeitos...

\section{Quadro 2}

(Quadro comparativo entre o FUNDEF e o FUNDEB)

\begin{tabular}{|c|c|c|}
\hline Características & FUNDEF & FUNDEB \\
\hline Composição dos recursos & ICMS+FPE+FPM+IPI-Ex+LC 87/96 & Idem + IPVA + ITR + ITCD \\
\hline Alíquota & $15 \%$ & $20 \%$ \\
\hline Complemento da União & $\begin{array}{c}\text { Segundo a EC 14: garantir mínimo igual à } \\
\text { média (o que equivaleria a cerca de } \mathrm{R} \$ 5 \\
\text { bilhōes/ano) } \\
\text { Real: } \mathrm{R} \$ 314 \text { milhōes em } 2006\end{array}$ & $\begin{array}{c}\mathrm{R} \$ 4,5 \text { bi em } 3 \text { anos } \\
\text { (depois: mínimo } 10 \% \text { da } \\
\text { contribuição dos estados e } \\
\text { municípios) }\end{array}$ \\
\hline $\begin{array}{l}\text { Critério de repartição dos } \\
\text { recursos entre estados e } \\
\text { municípios }\end{array}$ & $\begin{array}{l}\text { Alunos no Ensino Fundamental Regular } \\
\text { público }\end{array}$ & $\begin{array}{l}\text { Alunos da educação básica presencial: } \\
\text { pública + conveniadas [creche e pré } \\
\text { (por } 4 \text { anos) e ed. especial exclusiva] }\end{array}$ \\
\hline $\begin{array}{c}\text { Recursos da } \\
\text { complementação da } \\
\text { União para projetos }\end{array}$ & Não existe & $\begin{array}{c}\text { Até } 10 \% \\
\text { (para estados que recebem a } \\
\text { complementação) }\end{array}$ \\
\hline $\begin{array}{l}\text { Profissionais do } \\
\text { magistério }\end{array}$ & $60 \%$ & $60 \%$ \\
\hline Piso Salarial Nacional & Omite & $\begin{array}{l}\text { Deve ser aprovado até } 31 / 8 / 2007 \\
\text { (só profissionais do magistério) }\end{array}$ \\
\hline Custo-aluno qualidade & $\begin{array}{c}\text { A ser implantado a partir de } 31 / 12 / 2001 \\
\text { (Obs.: nunca foi) }\end{array}$ & Sem prazo para implantação \\
\hline
\end{tabular}

Fonte: Lei n. 11.494/2007

Da análise do Quadro 2, a principal conclusão a que se chega, e esta talvez seja a sua maior importância, é que o FUNDEB resgatou o conceito de educação básica como um direito. Nele estão incluídas as diferentes etapas e modalidades da educação básica. Neste sentido, estados e municípios não terão mais argumentos para investir apenas no ensino fundamental regular como acontecia com o FUNDEF. Na versão final do novo fundo foram incluídas as matrículas da educação infantil e da educação especial da rede conveniada sem fins lucrativos. Essa inclusão, que representa um duro golpe no princípio de que recursos públicos devem se destinar às instituiçôes públicas, decorreu da constatação de que um número significativo de prefeituras mantém convênios com aquelas instituições e sua exclusão significaria deixar milhares de crianças sem atendimento. $\mathrm{O}$ grande risco, em especial no que se refere às creches, onde a demanda reprimida é gigantesca em virtude do baixo atendimento, é que o crescimento das matrículas se dê pela via das instituições conveniadas, já que o repasse que o poder público faz a essas instituições é muito inferior aos custos do atendimento direto. Cabe ressaltar que essas diferenças não se referem a níveis distintos de eficiência do setor público versus 
privado, mas simplesmente porque o padrão de qualidade de oferta das instituições públicas é muito superior e, logo, os custos também o são. Esse risco de uma expansão da educação infantil pela via dos convênios com instituiçóes privadas sem fins lucrativos ficou ainda mais concreto quando a Lei n. 11.494/2007, que regulamenta o FUNDEB, por pressão dos governos estaduais, estabeleceu, para 2007, como fator de ponderação das creches, um índice que corresponde a apenas $80 \%$ do custoaluno das séries iniciais do ensino fundamental (fator 0,8). Para 2008, a mesma lei fixa para as creches em tempo integral (que são a maioria) um valor $10 \%$ acima daquele definido para as séries iniciais. Contudo, como sabem todos os secretários de Educação e pesquisadores, uma creche em tempo integral tem um custo-aluno que é, no mínimo, duas vezes maior que o custo-aluno das séries iniciais do ensino fundamental em tempo parcial. E isso por duas razóes simples: 1) atender em tempo integral e 2) a razão aluno/turma ser, na melhor das hipóteses, a metade. O já citado estudo da Campanha Nacional pelo Direito à Educação (Carreira \& Pinto, 2007) chegou a uma razão de 2,4 vezes entre o custo da creche em tempo integral e o custo das séries iniciais do ensino fundamental em tempo parcial. Entretanto, para que os alunos atendidos por meio das instituições conveniadas sejam contabilizados para efeito de recebimento dos recursos do fundo, a lei que regulamenta o FUNDEB estabeleceu uma série de exigências, entre elas a gratuidade para todos os alunos, o atendimento de padrōes de qualidade definidos pelo órgão normativo, a existência de projeto pedagógico e a certificação junto ao Conselho Nacional de Assistência Social ou órgão equivalente $\left(\operatorname{art} .8^{\circ}, \$ 2^{\circ}\right.$ ). Além disso, os recursos não são repassados diretamente às instituições, mas ao poder público municipal, que pode inclusive utilizar parte destes para a ampliação da rede própria (art. $8^{\circ}$, $\left.\$ 5^{\circ}\right)$. Para a faixa da pré-escola ( 4 e 5 anos) a lei permite a contabilização dos alunos atendidos em instituições conveniadas apenas até 2010.

Da análise do Quadro 2 constata-se como um dado positivo na lei do FUNDEB a definição de um prazo para que seja aprovado, por meio de lei, o Piso Salarial Profissional Nacional para os profissionais do magistério (art. 41). Trata-se de um avanço importante, em especial para as regiões mais pobres do país. Não obstante, não foram contemplados os demais trabalhadores da educação. Zeladores, inspetores de alunos, merendeiras e secretários são profissionais que mantêm intenso contato e convivência com os alunos, tendem a se fixar nas escolas (ao contrário 
A política recente de fundos para o financiamento da educação e seus efeitos...

de diretores e professores) e, por isso, são essenciais para o bom funcionamento delas, que depende essencialmente do trabalho coletivo. Além disso, o projeto de lei enviado pelo governo (PL n. 619/2007), que fixa o piso em R \$ 850/mês para uma jornada de 40 horas, tem sofrido fortes críticas da Confederação Nacional dos Trabalhadores da Educação (CNTE, 2007), pela forma pouco democrática com que a proposta foi elaborada, pois o piso não se articula a uma proposta de carreira profissional, pelo fato de este valor ser integralizado somente em 2010, porque não considera o nível de formação dos profissionais nem prevê tempo remunerado para atividades extraclasse. A regulamentação do fundo é também muito genérica no que se refere aos planos de carreira para a área e, assim, resta a expectativa de que o Conselho Nacional de Educação, agora com uma composição mais comprometida com uma escola pública de qualidade, estabeleça diretrizes que de fato assegurem a valorização de todos os profissionais da educação, ao contrário do que ocorreu com a resolução CNE/CEB n. 3/1997.

Outra inovação do FUNDEB encontra-se na previsão de que até $10 \%$ da complementação da União possa ser utilizada por meio de programas direcionados para a melhoria da qualidade da educação básica, nos termos de regulamentação a ser feita (art. $7^{\circ}$ da Lei n. 11.494/ 2007). Embora a intenção seja boa, permitindo o estímulo a projetos em regime de colaboração entre estados e municípios, ou voltados à qualificação de professores, a nossa história educacional sobre este tipo de iniciativa, que foi muito comum em relação aos recursos do salárioeducação, indica o predomínio de critérios político-partidários e a má utilização dos recursos.

Um retrocesso importante do FUNDEB, ante o FUNDEF, refere-se ao enfraquecimento do princípio do custo-aluno qualidade. A legislação do FUNDEF (EC-14) estabelecia que este valor mínimo não poderia ser inferior, inicialmente, à média nacional do valor por aluno daquele fundo, garantindo-se que, a partir de 31 de dezembro de 2001, o valor mínimo nacional deveria garantir um padrão mínimo de qualidade de ensino. Embora estes dois preceitos nunca tenham sido cumpridos, o fato de eles constarem em mandamento constitucional era um instrumento importante de luta para todos aqueles que defendem uma escola pública de qualidade. No FUNDEB, o princípio consta apenas na forma anódina do artigo 38 da lei regulamentadora, o qual estabelece que os entes da Federação deverão assegurar no financiamento da educação 
básica a melhoria da qualidade do ensino de forma a "garantir padrão mínimo de qualidade de ensino definido nacionalmente". Ou seja, nada além do que já consta no texto constitucional.

Outro aspecto da regulamentação do FUNDEB que ainda causará muitas controvérsias se refere à diferenciação nos fatores de ponderação do custo-aluno entre as diferentes etapas e modalidades de ensino.

\section{Quadro 3}

(Fatores de ponderação no valor/aluno para as diferentes etapas e modalidades de ensino - 2007)

\begin{tabular}{|l|c|}
\hline \multicolumn{1}{|c|}{ Etapa ou modalidade } & Fator de ponderação \\
\hline EJA & 0,7 \\
\hline Creche & 0,8 \\
\hline Pré-escola & 0,9 \\
\hline EF anos iniciais urbano (parcial) & 1,0 \\
\hline EF anos iniciais no campo (parcial) & 1,05 \\
\hline EF anos finais urbano (parcial) & 1,10 \\
\hline EF anos finais no campo (parcial) & 1,15 \\
\hline $\begin{array}{l}\text { E. Médio urbano (parcial), educ. especial, } \\
\text { indígena e quilombola }\end{array}$ & 1,20 \\
\hline $\begin{array}{l}\text { E. Médio no campo, E. Fundamental tempo } \\
\text { integral }\end{array}$ & 1,25 \\
\hline $\begin{array}{l}\text { E. Médio integral, EM com educ. } \\
\text { profissional }\end{array}$ & 1,30 \\
\hline
\end{tabular}

Fonte: Lei n. 11.494/2007.

Pelos índices apresentados no Quadro 3, que são aqueles em vigor para o ano de 2007, constata-se que o critério utilizado na sua definição esteve longe de ser o custo real dessas etapas e modalidades. $\mathrm{Na}$ verdade o que houve foi uma decisão política que teve como parâmetro a busca de um acordo mínimo entre estados e municípios. Como se sabe, as redes estaduais detêm a quase totalidade das matrículas públicas de ensino médio, e o mesmo é verdade para os municípios no que se refere à educação infantil. Portanto, a pressão dos governos estaduais 
A política recente de fundos para o financiamento da educação e seus efeitos...

deu-se, em um primeiro momento, com o intento de retirar do FUNDEB os alunos de creches. Esse esforço foi vitorioso, pois, de forma inexplicável, o projeto do Executivo enviado ao Congresso Nacional não contemplava essa modalidade. Contudo, a mobilização da sociedade civil organizada, em especial por intermédio da campanha "FUNDEB Pra Valer", e a atuação de parlamentares mais compromissados com a educação pública garantiram a inclusão das creches no FUNDEB. A busca de um entendimento mínimo que garantisse a aprovação do fundo impediu, contudo, que fossem tomados como parâmetro, no seu primeiro ano de funcionamento, fatores de ponderação que explicitassem as diferenças reais de custo. Assim, não há justificativa, por exemplo, para que um aluno de EJA custe menos que um aluno do ensino fundamental, a não ser que se tenha como objetivo oferecer-lhe uma educação de baixa qualidade. Estranho é também o ensino médio ter um fator de ponderação superior ao das séries finais do ensino fundamental $(1,2$ versus 1,1 ), uma vez que os seus professores possuem a mesma formação e no ensino médio, segundo dados do INEP, a razão alunos/turma é maior, o que reduz os custos. Como já comentamos, para os próximos anos a lei determina (art. 13, inc. I) que os fatores de ponderação levem em conta os custos reais de cada etapa, modalidade de ensino ou tipo de estabelecimento, tendo por base estudos a serem feitos pelo INEP. Contudo, considerando que caberá à recém-criada Comissão Intergovernamental de Financiamento para a Educação Básica de Qualidade (CIFEBQ) definir esses fatores de ponderação e que essa comissão será composta por cinco representantes da UNDIME, cinco representantes do CONSED e um representante do MEC, sem qualquer representação de pais, alunos e profissionais da educação, o mais provável é a prevalência de critérios de natureza fiscal.

No nosso entendimento, o adequado, no que se refere às ponderações, não é estabelecê-las em termos de etapas, modalidades ou tipos de estabelecimentos, mas sim em termos de condições de oferta. Em outras palavras, hoje todos os estudos de custo mostram, por exemplo, que, para uma mesma rede de ensino, um aluno do ensino médio custa menos que um aluno do ensino fundamental. Mas isso só acontece porque o ensino médio no Brasil funciona em espaços e turnos ociosos de escolas de ensino fundamental, com turmas superlotadas e sem qualquer recurso didático que permita atender os objetivos constantes no artigo 35 da LDB para essa etapa da educação básica. Portanto, só há 
sentido em fixar um fator maior para o ensino médio se ele for de fato oferecido em novas bases de atendimento. Por isso, acreditamos que os fatores de ponderação devem estar, antes de mais nada, associados de forma objetiva às condições em que a oferta se dará, pautando-se por critérios como: duração da jornada do professor e do aluno, nível de formação dos profissionais, razão alunos/turma, presença de laboratórios, bibliotecas, entre outros insumos.

Não pode ficar sem menção, também, o limite incluído no FUNDEB para a contabilização dos alunos da EJA, de tal forma que os recursos destinados a essa modalidade não podem ser superiores a $15 \%$ dos recursos do fundo em cada unidade da Federação (art. 11 da Lei n. 11.494/2007). Embora essa limitação não impeça uma ampliação significativa das matrículas perante a situação atual, essa medida, juntamente com o fator de ponderação 0,7 para a EJA, é um sinal claro de desrespeito aos direitos dos jovens e adultos trabalhadores que não tiveram garantido pelo Estado o acesso ou a permanência na escola na idade mais adequada.

Por fim, cabe comentar um aspecto em que o FUNDEB representou um indiscutível avanço ante o FUNDEF. Trata-se do capítulo VI da Lei n. 11.494/2007, que trata do controle social dos recursos do Fundo. Houve um fortalecimento da representação dos usuários da escola nestes conselhos, garantindo-se a participação de pelo menos dois pais e dois estudantes, além de um representante dos conselhos tutelares nos conselhos de âmbito municipal. A legislação estabeleceu também uma série de impedimentos que atinge parentes de membros do Executivo, prestadores de serviços, pais que ocupem cargos ou funções de confiança, com o objetivo de dificultar (já que impedir é quase impossível) o controle do Executivo sobre esses conselhos (regra que se estende aos Conselhos Municipais de Educação, nos termos do $₫ 2$ do art. 37), como a experiência dos conselhos do FUNDEF mostrou ocorrer em profusão. Neste mesmo sentido vem a proibição de que o representante do governo gestor dos recursos do fundo, em cada esfera de governo, ocupe a presidência do órgão, a qual deve ser eleita pelos conselheiros. Também foram ampliadas as atribuições dos conselhos, os quais, além de supervisionar o Censo Escolar e acompanhar e fiscalizar os gastos com os recursos do FUNDEB, terão também a função de supervisionar a elaboração da proposta orçamentária anual, acompanhar a aplicação dos recursos e a prestação de contas do Programa Nacional 
A política recente de fundos para o financiamento da educação e seus efeitos...

de Apoio ao Transporte Escolar (PNATE) e do Programa de Apoio aos Sistemas de Ensino para Atendimento à Educação de Jovens e Adultos (art. 24). Como aspectos negativos da regulamentação, ressaltamos o preceito que impede que os conselhos possuam uma estrutura administrativa própria para subsidiar a sua ação, ficando, portanto, na dependência da, nem sempre presente, boa vontade dos Executivos que lhes cabe fiscalizar. $\mathrm{O}$ fato de o legislador não adotar um critério geral de paridade entre os diferentes segmentos, como acontece, por exemplo, nos conselhos da saúde, permite também que os Executivos inflem a sua representação. Entretanto, cabe ressaltar que eles permanecem como conselhos de fiscalização, sem poder real para definir as políticas para a área. Neste aspecto, a nova atribuição conquistada de "supervisionar" (palavra ambígua) a elaboração da proposta orçamentária pode se configurar como um salto de qualidade na participação da sociedade civil na definição e elaboração de políticas públicas. Estranho também é a lei ter criado a já citada Comissão Intergovernamental de Financiamento para a Educação Básica de Qualidade ( $\mathrm{CIFEBQ}$ ), a qual não estava prevista na EC n. 53/2006 que criou o FUNDEB, com atribuiçóes que, no nosso entendimento, caberiam ao Conselho Federal do FUNDEB.

Concluindo, muito embora o FUNDEB represente um avanço ante o FUNDEF, ao resgatar o conceito de educação básica e ao fortalecer o controle social, ele não enfrentou os dois principais problemas de nossa política de fundos: 1) a inexistência de um valor mínimo por aluno que assegure um ensino de qualidade e que impeça as disparidades regionais; 2) embora o fundo seja único no âmbito de cada unidade da Federação, os alunos permanecem atendidos por duas redes distintas, com padrōes de funcionamento e de qualidade distintos e que dificilmente conseguem estabelecer um regime de colaboração. Para enfrentar essas questões, vemos duas saídas. A primeira delas é ampliar a parcela da União no financiamento da educação básica. É inadmissível que o governo federal, que, segundo dados da Receita Federal, ficou, em 2005 , com $58 \%$ da carga tributária do país, o equivalente a $21,6 \%$ do PIB, limite-se a contribuir para o FUNDEB com menos de $0,2 \%$ do PIB, ou seja, um valor inferior a um centésimo de sua receita tributária disponível. Se a União incluísse no fundo cerca de $1 \%$ do PIB e estados e municípios ampliassem a sua aplicação em manutenção e desenvolvimento do ensino em mais $5 \%$ de sua receita líquida de impostos (o que geraria recursos adicionais da ordem de $0,6 \%$ do $\mathrm{PIB}$ ) estariam dados os 
primeiros passos para se garantir um gasto por aluno que propiciasse em cada escola do país um ensino com um padrão mínimo de qualidade.

Um segundo e importante passo então teria de ser dado no que se refere à gestão das escolas. E trata-se de uma medida que, com o FUNDEB, encontra-se muito facilitada. Ao contrário de escolas estaduais ou municipais de educação básica, teríamos apenas escolas públicas, e os recursos do fundo, em vez de se dirigir às secretarias estaduais e municipais de Educação, ficariam sob supervisão dos conselhos locais do FUNDEB, que se transformariam em conselhos gestores, ficando responsáveis pela aplicação dos recursos, administração de pessoal e avaliação de todos os alunos das escolas sob sua jurisdição. Esses conselhos perderiam seu caráter municipal, embora a sua jurisdição possa ser o município, e se estruturariam como instância pública autônoma perante os estados e municípios, regulados por lei federal que garantisse hegemonia da sociedade civil em sua composição e os princípios da gestão democrática em seu funcionamento. Esta, em nosso entendimento, no que se refere à gestão, seria a única forma de dar fim à atual "guerra fiscal" entre estados e municípios pelos alunos que "rendem" mais no fundo; guerra que tem como corolário o abandono ou a oferta precária para aqueles de maior custo (creches, zona rural, EJA etc.). Uma escola pública única, financiada com presença relevante do governo federal, com a função de reduzir as disparidades regionais e garantir um padrão mínimo de qualidade, administrada de forma coletiva pelos principais interessados em uma escola pública de qualidade: pais, alunos e profissionais da educação.

Recebido em julho de 2007 e aprovado em agosto de 2007.

\section{Nota}

1. Não consideramos a matrícula da rede federal de educação básica, pois seu peso é insignificante no total da matrícula pública.

Referências bibliográficas

ARELARO, L.R.G.; KRUPPA, S.M.P. A educação de jovens e adultos. In: Oliveira, R.P.; Adrião, T. Organização do ensino no Brasil: níveis e 
A política recente de fundos para o financiamento da educação e seus efeitos...

modalidades na Constituição Federal e na LDb. São Paulo: Xamã, 2002. p. 89-107.

BRASIL. Decreto n. 6.091, de 24 de abril de 2007. Divulga os parâmetros de operacionalização do FUNDEB para o ano de 2007. Diário Oficial da Uniāo, Brasília, DF, 24 abr. 2007.

BRASIL. Emenda Constitucional n. 14, de 12 de setembro de 1996. Modifica os art. 34, 208, 211 e 212 da Constituição Federal e dá nova redação ao art. 60 do Ato das Disposições Constitucionais Transitórias. Diário Oficial da União, Brasília, DF, 13 set. 1996.

BRASIL. Emenda Constitucional n. 53, de 19 de dezembro de 2006. Dá nova redação aos art. 7º, 23, 30, 206, 208, 211 e 212 da Constituição Federal e ao art. 60 do Ato das Disposições Constitucionais Transitórias. Diário Oficial da Uniāo, Brasília, DF, 20 dez. 2006.

BRASIL. Lei n. 9.394, de 20 de dezembro de 1996. Dispõe sobre as Diretrizes e Bases da Educação Nacional. Diário Oficial da União, Brasília, DF, 23 dez. 1996.

BRASIL. Lei n. 9.424, de 24 de dezembro de 1996. Dispõe sobre o Fundo de Manutenção e Desenvolvimento do Ensino Fundamental e de Valorização do Magistério - Fundef. Diário Oficial da União, Brasília, DF, 26 dez. 1996.

BRASIL. Lei n. 10.172, de 9 de janeiro de 2001. Aprova o Plano Nacional de Educação e dá outras providências. Diário Oficial da Uniāo, Brasília, DF, 10 jan. 2001.

BRASIL. Lei n. 11.494, de 20 de junho de 2007. Regulamenta o Fundo de Manutenção e Desenvolvimento da Educação Básica e de Valorização dos Profissionais da Educação - FUndeb, de que trata o art. 60 do Ato das Disposições Constitucionais Transitórias; altera a Lei n. 10.195, de 14 de fevereiro de 2001; revoga dispositivos das Leis n. 9.424, de 24 de dezembro de 1996, 10.880, de 9 de junho de 2004, e 10.845, de 5 de março de 2004; e dá outras providências. Diário Oficial da União, Brasília, DF, 21 jun. 2007.

BRASIL. Ministério da Educação. Instituto Nacional de Estudos e Pesquisas Educacionais (INEP). Censo escolar. Brasília, DF: MEC/INEP, 1991-2006. 
BRASIL. Projeto de lei no 619, de 2 de abril de 2007. Regulamenta o art. 60, inciso III, alínea "e", do Ato das Disposiçôes Constitucionais Transitórias, para instituir o piso salarial profissional nacional para os profissionais do magistério público da educação básica. Diário Oficial da União, Brasília, DF.

BRASIL. Resolução CNE/CEB n. 3, de 8 de outubro de 1997. Fixa diretrizes para os novos planos de carreira e de remuneração para o magistério dos estados, do Distrito Federal e dos municípios. Diário Oficial da União, Brasília, DF, 13 out. 1997.

BREMAEKER, F.E.J. O impacto do FUNDEF nas finanças municipais em 2002. Rio de Janeiro: IBAM, 2003. (Estudos especiais, v. 59).

BREMAEKER, F.E.J. A receita tributária dos municípios brasileiros em 2003. Rio de Janeiro: IBAM, 2004. (Estudos especiais, v. 78).

BREMAEKER, F.E.J. O impacto do FUNDEB nas finanças dos municipios brasileiros. Rio de Janeiro: IBAM, 2007. (Estudos especiais, v. 190).

CARREIRA, D.; PINTO, J.M.R. Custo aluno-qualidade inicial: rumo à educação pública de qualidade no Brasil. São Paulo: Global, 2007.

CONFEDERAÇÃO NACIONAL DOS TRABALHADORES DA EDUCAÇÃO. Piso salarial profissional nacional do magistério: análise do Projeto de Lei n. 619/2007. Brasília, DF: CNTE, 2007. Disponível em: <http://www.cnte.org.br>. Acesso em: jul. 2007.

DIDONET, V. A educação infantil na educação básica e o Fundeb. In: Lima, M.J.R.; Didonet, V. (Org.). FUNDEB: avanços na universalização da educação básica. Brasília, DF: INEP, 2006. p. 31-48.

ORGANIZATION FOR ECONOMIC CO-OPERATION AND DEVELOPMENT (OECD). Education at a glance. 2005. Disponível em: <http://www.oecd.org/dataoecd/2/12/35286348.xls>. Acesso em: 15 jul. 2007.

PINTO, J.M.R. Requisitos para a construção do FUnDEB. In: LimA, M.J.R.; Didonet, V. (Org.). FUNDEB: avanços na universalização da educação básica. Brasília, DF: INEP, 2006. p. 89-104. 